\title{
The electrodiagnostic characteristics of Glycogen Storage Disease Type III
}

\author{
Lisa D. Hobson-Webb, MD, ${ }^{1}$ Stephanie L. Austin, MS, MA, ${ }^{2}$ Deeksha S. Bali, PhD, ${ }^{2}$ \\ and Priya S. Kishnani, $M D^{2}$
}

\begin{abstract}
Purpose: Glycogen Storage Disease Type III, also known as debrancher deficiency or Cori disease, is an autosomal recessive disorder recognized for both its hepatic and muscle manifestations. The neuromuscular manifestations of Glycogen Storage Disease Type III are not well characterized. In this study, we attempt to better define the disorder. Methods: The medical records of 40 patients with Glycogen Storage Disease Type III seen at Duke University during 1990-2009 were reviewed. The medical records of all patients with nerve conduction studies and/or electromyography were examined. Results: Twelve patients with Glycogen Storage Disease Type III (aged 5-55 years) had undergone nerve conduction studies \pm electromyography. Three of these cases are presented in detail. Nine patients had Glycogen Storage Disease Type IIIa, two patients had Glycogen Storage Disease Type $\mathrm{IIIb}$, and the clinical subtype of one patient was unknown. All had nerve conduction studies and of those nerves tested, abnormalities in the median motor response were most common, corresponding to previously described, intrinsic hand muscle weakness. Electromyography was performed in eight patients and myopathic findings were present in six individuals. Abnormal electrodiagnostic findings were more common in older patients. The two patients with Glycogen Storage Disease Type IIIb had electrodiagnostic evidence of nerve involvement with minor myopathic findings. Conclusions: The neuromuscular manifestations of Glycogen Storage Disease Type III include myopathy and neuropathy and are more likely to occur with increasing age, even in those diagnosed with Glycogen Storage Disease Type IIIb. Intrinsic hand muscle weakness is likely due to a combination of nerve and muscle dysfunction, a finding that may have implications for treatment. Genet Med 2010:12(7):440-445.
\end{abstract}

Key Words: debrancher deficiency, GSD III, myopathy, neuropathy, electromyography, nerve conduction studies

C lycogen Storage Disease Type III (GSD III), also known as debrancher deficiency or Cori disease, is primarily recognized for its hepatic manifestations. It is an autosomal recessive disorder that results from deficiency of the glycogen debranching enzyme located at chromosome $1 \mathrm{p} 21 .{ }^{1}$ The disorder commonly presents in infancy with hypoglycemia, hepatomegaly, and seizures. ${ }^{2}$ The neuromuscular manifestations of GSD III have been reported but are not as well defined. In this study, the neuromuscular manifestations of GSD III in 12 patients are described.

From the ${ }^{1}$ Division of Neurology, Department of Medicine and ${ }^{2}$ Division of Medical Genetics, Department of Pediatrics, Duke University Medical Center, Durham, North Carolina.

Lisa D. Hobson-Webb, MD, DUMC 3403, Clinic 1L, Trent Drive, Duke University Medical Center. Durham, NC 27710. E-mail: lisa.hobsonwebb@, duke.edu.

Disclosure: The authors declare no conflict of interest.

Submitted for publication August 20, 2009.

Accepted for publication December 1, 2009

Published online ahead of print January 12, 2010.

DOI: $10.1097 /$ GIM.0b013e3181cd735b

\section{BACKGROUND}

Glycogen storage disorders (GSD) result from enzymatic deficiencies that prevent the appropriate formation, storage, and/or utilization of glycogen. GSD III is an autosomal recessive disorder that results from a deficiency of the glycogen debranching enzyme located on chromosome $1 \mathrm{p} 21 .{ }^{1}$ It occurs in $\sim 1$ of 100,000 live births in North America but may be under-recognized. ${ }^{3}$ The incidence is variable across different ethnic groups. ${ }^{3-5}$ Enzyme activity is most pronounced in the liver and muscle, and clinical phenotypes reflect this distribution of involvement.

There are two major subtypes of GSD III. GSD IIIa is most common $(80 \%)$ and results in both hepatic and muscular involvement. GSD IIIb affects only the liver and enzyme activity in muscle is normal. ${ }^{2}$ This is secondary to differential splicing of the glycogen debranching enzyme gene (AGL).6,7 GSD III is typically diagnosed within the first year of life and symptoms of hepatic involvement are prominent. Infants commonly display hypoglycemia, hepatomegaly, short stature, and dyslipidemia. ${ }^{8}$ Muscular involvement is often not evident until much later. ${ }^{2,9-11}$

Recognition of GSD III has lead to increasing knowledge about the natural history of the disorder. In childhood, patients are managed with complex-carbohydrate meals and cornstarch supplementation, along with a high protein diet. ${ }^{12,13}$ Hepatic symptoms often subside at puberty and in the past, dietary modifications were discarded. ${ }^{12}$ Recently, it has become apparent that liver issues in GSD III do not end in adolescence. A recent report by Demo et al. ${ }^{14}$ described hepatocellular carcinoma as a potential long-term complication of the disorder, ${ }^{15-18}$ and cirrhosis has long been known to occur. ${ }^{15-21}$ In addition, the late neuromuscular manifestations of GSD III are beginning to be appreciated. Although there are scattered case reports and series describing weakness, myopathy, and even neuropathy in patients with GSD III, much remains to be learned. . $^{2,10,11,22-27}$

In this report, the neuromuscular function of 12 GSD III patients at Duke University Medical Center is examined. This is the first study to analyze the neuromuscular, electrodiagnostic, and DNA analysis findings in patients with GSD IIIa and IIIb, and the first report of neuromuscular involvement in patients with GSD IIIb.

\section{MATERIALS AND METHODS}

After the approval of Institutional Review Board, a chart review of 40 patients with GSD III seen at Duke University Medical Center between 1990 and 2009 was performed. Twelve patients were identified who had undergone nerve conduction studies (NCS) \pm electromyography (EMG). A diagnosis of GSD III was made based on increased glycogen content, altered ratio of glucose-1-phosphate/glucose, evidence of debrancher enzyme deficiency in liver and/or muscle biopsy, and DNA mutation analysis. Subtyping of GSD III was based on presence or absence of enzyme activity in muscle (liver and muscle involved in GSD IIIa, liver only with normal muscle enzyme 
activity in IIIb) or the presence specific mutations in exon 3 of AGL gene, known to occur only in GSD IIIb.

The charts of these patients were reviewed and information regarding age, gender, hepatic function, cardiac function, motor strength examination, sensory examination, creatine phosphokinase (CPK) levels, and NCS/EMG was recorded.

All nerve conduction and EMG studies were performed in the Duke University Electromyography Laboratory by trained electrodiagnosticians from 1990 to 2009 . The equipment used varied over the years, but laboratory techniques and standards were unchanged during this time. All NCS were performed recording at $34^{\circ} \mathrm{C}$ using standard recording distances for the laboratory. EMG was performed using a concentric needle on selected muscles when deemed necessary by the examiner.

\section{RESULTS}

During 1990-2009, 12 patients with GSD III were identified who had undergone NCS \pm EMG at Duke University Medical Center. The patient characteristics are summarized in Table 1. All patients had hepatic involvement of varying degree, while only 4 of 12 patients showed cardiac manifestations. Cardiac disease resulted in transplant in Patient 8, but the other patients had asymptomatic mild left ventricular hypertrophy. There was no direct correlation between the presence of cardiac abnormalities and neuromuscular dysfunction in this sample population. CPK levels were available for 11 of 12 patients and all were elevated with the exception of Patient 12, who had GSD IIIb.

Table 2 outlines the physical examination and electrodiagnostic findings of these patients in detail. Older patients seemed to show more changes on NCS and EMG. In addition, the median motor response seemed to be disproportionately involved in a pattern not always consistent with simple carpal tunnel syndrome. For example, Patients 3, 10, and 11 had abnormalities in median motor responses without changes in median sensory function. With carpal tunnel syndrome, the sensory responses are almost always affected first. Another unexpected finding was the paucity of spontaneous activity on EMG (only three of eight patients), which has previously been prominently noted in other patients with GSD III. ${ }^{9,10,11,16,18}$

\section{CASE REPORTS}

The following three case reports are provided to better illustrate the neuromuscular manifestations in GSD III, including the finding of neuromuscular disease in a patient diagnosed with GSD IIIb.

\section{Table 1 Patient characteristics}

\begin{tabular}{|c|c|c|c|c|c|c|c|c|c|c|}
\hline \multirow[b]{2}{*}{ Case } & \multirow{2}{*}{$\begin{array}{l}\mathrm{Age}^{a} \\
(\mathrm{yr})\end{array}$} & \multirow[b]{2}{*}{ Gender } & \multicolumn{2}{|c|}{ Involvement } & \multirow{2}{*}{$\begin{array}{l}\text { Maximum } \\
\text { CPK (U/L) }\end{array}$} & \multirow[b]{2}{*}{ Genetic variant } & \multirow[b]{2}{*}{ Allele } & \multirow[b]{2}{*}{ Region } & \multirow{2}{*}{$\begin{array}{l}\text { Amino acid } \\
\text { change }\end{array}$} & \multirow[b]{2}{*}{ Effect } \\
\hline & & & Hepatic $^{b}$ & $\operatorname{Cardiac}^{c}$ & & & & & & \\
\hline 1 & 5 & $\mathrm{~F}$ & Yes & Yes & 2,290 & c.1276delG & Het & Exon 11 & p.Val426LfsX12 & Frameshift/deletion $^{d}$ \\
\hline 2 & 11 & $\mathrm{~F}$ & Yes & No & 1,027 & c. $4260-12 A>G$ & Het & Intron 32 & - & Intronic splicesite \\
\hline 3 & 13 & M & Yes & Yes & 9,264 & Exon 3 del & Hom & Exon 3 & p.exon3del & Exon deletion \\
\hline 4 & 17 & M & Yes & $\mathrm{NA}^{e}$ & NA & Unknown & - & - & - & - \\
\hline 5 & 17 & $\mathrm{~F}$ & Yes & Yes & 678 & c. 3965 delT & Hom & Exon 31 & p.Val1322fsX1348 & Frameshift/deletion \\
\hline \multirow[t]{2}{*}{6} & 33 & $\mathrm{~F}$ & Yes & No & 1,195 & c.410_413delTGGG & Het & Exon 5 & p.Leu137YfsX20 & Frameshift/deletion \\
\hline & & & & & & c. $2039 \mathrm{G}>\mathrm{A}$ & Het & Exon 17 & p.Trp680X & Nonsense/truncating \\
\hline \multirow[t]{2}{*}{7} & 35 & $\mathrm{~F}$ & Yes & No & 1,114 & c. $2590 \mathrm{C}>\mathrm{T}$ & Het & Exon 21 & p.Arg864X & Nonsense/truncating \\
\hline & & & & & & c. 4529 dupA & Het & Exon 35 & p.Tyr1510X & Nonsense/truncating \\
\hline \multirow[t]{2}{*}{8} & 45 & M & Yes & Yes & 1,747 & c. $100 \mathrm{C}>\mathrm{T}$ & Het & Exon 4 & p.Arg33X & Nonsense/truncating ${ }^{d}$ \\
\hline & & & & & & c. $2590 \mathrm{C}>\mathrm{T}$ & Het & Exon 21 & p.Arg864X & Nonsense/truncating ${ }^{d}$ \\
\hline \multirow[t]{2}{*}{9} & 45 & M & Yes & No & 392 & c.17_18delAG & Het & Exon 3 & p.Gln6HisfsX20 & Frameshift/deletion \\
\hline & & & & & & c. $2039 \mathrm{G}>\mathrm{A}$ & Het & Exon 17 & p.Trp680X & Nonsense/truncating \\
\hline \multirow[t]{2}{*}{10} & 48 & M & Yes & No & 1,439 & c. $1963 \mathrm{G}>\mathrm{A}$ & Het & Exon 16 & p.Gly655Arg & Missense $^{d}$ \\
\hline & & & & & & c. $3701-17 \mathrm{~T}>\mathrm{A}$ & Het & Intron 28 & - & Intronic splicesite ${ }^{d}$ \\
\hline \multirow[t]{2}{*}{11} & 53 & $\mathrm{~F}$ & Yes & No & 2,209 & c. $2155 \mathrm{C}>\mathrm{T}$ & Het & Exon 17 & p.Gln719X & Nonsense/truncating ${ }^{d}$ \\
\hline & & & & & & c. $3980 \mathrm{G}>\mathrm{A}$ & Het & Exon 31 & p.Trp1327X & Nonsense/truncating \\
\hline \multirow[t]{2}{*}{12} & 55 & M & Yes & No & 216 & c. $16 \mathrm{C}>\mathrm{T}$ & Het & Exon 3 & p.Gln6X & Nonsense/truncating \\
\hline & & & & & & c. $2039 \mathrm{G}>\mathrm{A}$ & Het & Exon 17 & p.Trp680X & Nonsense/truncating \\
\hline $\begin{array}{l}{ }^{{ }^{a}} \mathrm{Age} \\
{ }^{b} \mathrm{Hep} \\
{ }^{c} \mathrm{Carc} \\
{ }^{c} \mathrm{Not} \\
{ }^{2}\end{array}$ & ne c & $\mathrm{ecc}$ & in stu & d ele & graphy. & rmal imaging & $\tau_{\delta}$ & atone & $\begin{array}{l}\text { cirrhosis, or } \\
\text { ation/heart tr }\end{array}$ & ic dysfunction. \\
\hline
\end{tabular}


Table 2 Clinical and electrodiagnostic findings

\begin{tabular}{|c|c|c|c|c|c|}
\hline Case & $\begin{array}{l}\text { Pattern of } \\
\text { weakness }\end{array}$ & $\begin{array}{c}\text { Sensory } \\
\text { examination }\end{array}$ & $\begin{array}{c}\text { Motor nerve conduction } \\
\text { studies }\end{array}$ & $\begin{array}{c}\text { Sensory nerve } \\
\text { conduction studies }\end{array}$ & Electromyography results \\
\hline 1 & Normal & Normal & $\begin{array}{l}\text { Peroneal: mild slowing; } \\
\text { Median: NL }\end{array}$ & Sural, median: NL & Normal \\
\hline 2 & Normal & Normal & Peroneal, ulnar: NL & Sural, median: NL & Not performed \\
\hline 3 & Normal & Normal & $\begin{array}{l}\text { Peroneal: NL; median: mild } \\
\text { slowing }\end{array}$ & Sural, median: NL & Normal \\
\hline 4 & Unknown & Unknown & Not performed & Sural: NL & Not performed \\
\hline 5 & Normal & Normal & Peroneal, ulnar: NL & Sural, median: NL & Not performed \\
\hline 6 & $\begin{array}{l}\text { Mild proximal } \\
\text { lower extremity } \\
\text { weakness }\end{array}$ & Normal & Peroneal, median: NL & Sural, median: NL & $\begin{array}{l}\text { Single run of positive sharp waves in } \\
\text { anterior tibialis; scattered } \\
\text { myopathic }{ }^{a} \text { MUPs in limb } \\
\text { muscles; APB with neuropathic }{ }^{b} \\
\text { MUPs }\end{array}$ \\
\hline 7 & $\begin{array}{l}\text { Proximal limbs; } \\
\text { intrinsic hand } \\
\text { muscles }\end{array}$ & Normal & Peroneal, tibial, median: NL & Sural, median: NL & $\begin{array}{l}\text { SA present: positive sharp waves and } \\
\text { complex repetitive discharges; } \\
\text { myopathic MUPs in proximal } \\
\text { limbs and hands }\end{array}$ \\
\hline 8 & $\begin{array}{l}\text { Proximal \& distal } \\
\text { limbs; intrinsic } \\
\text { hand muscles }\end{array}$ & Normal & $\begin{array}{l}\text { Peroneal: NL; median: low } \\
\text { amplitude }\end{array}$ & Sural, median: NL & No SA; myopathic MUPs \\
\hline 9 & Normal & Normal & $\begin{array}{l}\text { Peroneal: low amplitude; } \\
\text { median: prolonged DL }\end{array}$ & $\begin{array}{l}\text { Sural, ulnar: NL; median: } \\
\text { prolonged DL, low } \\
\text { amplitude }\end{array}$ & $\begin{array}{l}\text { No SA; myopathic MUPs in } \\
\text { proximal limbs; neuropathic MUPs } \\
\text { in median- innervated hand } \\
\text { muscles }\end{array}$ \\
\hline 10 & $\begin{array}{l}\text { Normal; developed } \\
\text { diffuse } \\
\text { weakness later }\end{array}$ & Normal & $\begin{array}{l}\text { Peroneal, ulnar: NL; median: } \\
\text { diffuse slowing, low } \\
\text { amplitude }\end{array}$ & Sural, median: NL & Not performed \\
\hline 11 & $\begin{array}{l}\text { Proximal limbs; } \\
\text { intrinsic hand } \\
\text { muscles }\end{array}$ & $\begin{array}{l}\text { Reduced } \\
\text { sensation } \\
\text { in feet }\end{array}$ & $\begin{array}{l}\text { Peroneal: NR; tibial: low } \\
\text { amplitude; median: low } \\
\text { amplitude, slowing }\end{array}$ & $\begin{array}{l}\text { Sural, radial: NL; ulnar: } \\
\text { low amplitude, slow }\end{array}$ & No SA; myopathic MUPs \\
\hline 12 & Normal & Normal & $\begin{array}{l}\text { Peroneal: NL; median: } \\
\text { prolonged DL; ulnar: NL }\end{array}$ & $\begin{array}{l}\text { Sural: NR; ulnar: NL; } \\
\text { median: prolonged DL }\end{array}$ & $\begin{array}{l}\text { Single run of positive sharp waves in } \\
\text { anterior tibialis; scattered } \\
\text { myopathic MUPs in limb muscles; } \\
\text { APB with neuropathic MUPs }\end{array}$ \\
\hline
\end{tabular}

NL, normal; MUP, motor unit potential; SA, spontaneous activity; DL, distal latency; NR, no response.

${ }^{a}$ Myopathic motor unit potentials defined by short duration, low-amplitude polyphasic motor unit potentials with early recruitment.

${ }^{b}$ Neuropathic motor unit potentials defined by long duration, large-amplitude motor unit potentials with reduced recruitment.

\section{Case 1}

Patient 11 was a Caucasian woman initially noted to have hepatomegaly on a well child examination only 1 year after GSD III was initially described. She did not receive any care directed at her underlying disorder and had mild delay in developmental milestones. She also noted decreased endurance when compared with her peers. At the age of 18 years, she was diagnosed with GSD III by liver biopsy.

In her $20 \mathrm{~s}$ and $30 \mathrm{~s}$, she had mild transaminitis and increasing muscle weakness. At the age of 39 years, she sought medical attention and began dietary modifications. A muscle biopsy at the age of 42 years revealed increased glycogen content and deficiency of the debrancher enzyme, confirming the diagnosis of GSD IIIa. By the age of 53 years, she used a wheelchair to ambulate and was unable to brush her teeth or hair without supporting her arm. She also noted painful paresthesias in her feet and distal legs. Clinical examination showed four-fifth strength of the proximal upper extremities and three-fifth strength of the proximal lower extremities. Distal lower extremity strength was four-fifth. Some wasting of the intrinsic hand muscles was noted. CPK levels were 1959-2209 U/L (reference, 20-200). Transthoracic echocardiography was normal.

NCS demonstrated an absent peroneal motor response and reduced amplitude tibial motor response of $1.1 \mathrm{mV}$ (normal $>2.8 \mathrm{mV}$ ). The sural sensory response was normal. The median motor response had a prolonged distal latency of 5.6 milliseconds (normal $<4.4$ milliseconds) with reduced amplitude of $3.7 \mathrm{mV}$ (normal $>4.2 \mathrm{mV}$ ). The median sensory responses had moderately prolonged distal latencies with normal amplitudes. The ulnar sensory responses demonstrated prolonged distal latencies and reduced amplitudes. EMG of the anterior tibialis demonstrated complex, short duration motor unit potentials with early recruitment, a pattern consistent with myopathy. No spontaneous activity was observed. 


\section{Case 2}

Patient 8 was a 45-year-old Caucasian man initially diagnosed with GSD I at birth based on his hepatic manifestations, as were two of his three older brothers. Over the course of his childhood, he was noted to have delayed motor milestones and did not walk until the age of 5 years. At the age 12 of years, he underwent a muscle biopsy and his diagnosis was changed to GSD IIIa. He began to have cardiac difficulties at the age of 16 years and a pacemaker was implanted for sick sinus syndrome. He had continued difficulties with hepatic and cardiac disease over the years, developing secondary renal dysfunction. He had a liver, heart, and kidney transplant at the age of 40 years.

At the age of 45 years, Patient 8 presented to the neuromuscular clinic for the evaluation of progressive weakness. At the time of evaluation, he was unable to open jars or walk more than 1.5 city blocks. On examination, there was atrophy of the right $>$ left intrinsic hand muscles and reduced muscle bulk throughout the upper and lower extremities. Strength was graded four-fifth in the proximal and distal upper and lower extremities, while facial strength was normal. He displayed a Trendelenburg gait and used his arms to rise from a seated position. A CPK level was $1,747 \mathrm{U} / \mathrm{L}$ with mild elevation of aspartate transaminase at $69 \mathrm{U} / \mathrm{L}$ (normal, 15-41 U/L).

NCS of the upper and lower extremities were normal with the exception of reduced amplitude of the median motor response $(3.4 \mathrm{mV})$. EMG demonstrated no spontaneous activity, but myopathic appearing motor unit potentials were seen in the deltoid, vastus lateralis, and extensor digitorum communis.

This case illustrates that liver transplantation is not curative in GSD IIIa and may not halt progression of associated neuromuscular disease.

\section{Case 3}

Patient 9 was a 45-year-old man diagnosed with GSD III confirmed by liver biopsy at the age of 4 years after he was noted to have hepatomegaly. The GSD III subtype was not further characterized at that time. He was tall for his age, but was noted to have mild motor delay, walking at around 20 months. He was managed with dietary modifications and had no difficulties throughout his childhood. He played American football in his teen years and continued to play at the collegiate level.

As an adult, he was employed in construction and performed heavy physical labor. At the age of 35 years, he began to note some mild distal lower extremity numbness along with forearm cramping following exertion. Over the next few years, he noted weakness in his proximal legs when climbing stairs and loss of grip strength. The paresthesias in his feet remained and he began to note intermittent tingling of his fingertips.

Clinical examination revealed a muscular individual without any evidence of weakness. Reflexes and sensation were normal. A CPK level was mildly elevated on the two occasions; it was checked at 292 and $392 \mathrm{U} / \mathrm{L}$ (normal 30-220 U/L) and there was mild transaminitis. Echocardiography was normal.

NCS revealed marked reduction in peroneal motor amplitudes $(0.8 \mathrm{mV})$ with borderline slowing of $41 \mathrm{~m} / \mathrm{second}$ (normal $>41 \mathrm{~m} /$ second). The median motor response had a moderately prolonged distal latency of 5.0 milliseconds (normal $<4.4$ milliseconds) but was otherwise normal. The median palmar and digital sensory responses also had prolonged distal latencies and reduction in amplitude, while ulnar sensory responses were normal. EMG revealed patchy areas of small, complex (myopathic) motor unit potentials in the tibialis anterior and vastus lateralis, while reduced recruitment was seen in the abductor pollicis brevis. The findings on NCS and EMG are of particular interest given the lack of weakness, atrophy, or sensory loss on clinical examination. A muscle biopsy was subsequently obtained on this patient and it showed normal glycogen content and structure (G-1-P/Glu ratio) and normal debranching enzyme activity, thus confirming the clinical diagnosis of GSD IIIb. DNA analysis of AGL gene also confirmed a diagnosis of GSD IIIb based on the presence of a common mutation, c.17_18delAG (in exon 3) and the same stop codon mutation found in the other IIIb patient in this study (Patient 12, Table 1).

\section{DISCUSSION}

GSD III is a disorder that was not described until the $1950 \mathrm{~s}^{28}$ Following its recognition, research focused on the hepatic manifestations in children. It was initially thought that the disease became virtually asymptomatic at puberty and affected individuals often ceased dietary therapies. More recently, there is renewed interest in the long-term complications of GSD III, not only hepatic cirrhosis and carcinoma, but the impact of the disorder on neuromuscular function.

To date, literature on the neuromuscular manifestations of GSD III has been limited. There have been scattered case reports and case series since the 1970s, but a comprehensive study has not been performed.2,9-11,22-27 This is likely secondary to the fact that mild weakness went unnoticed in most children. There is even less data on the electrodiagnostic assessment of GSD III. A summary of prior reports that include substantial details of the NCS/EMG findings of GSD III is provided in Table 3 .

In these previous studies, 13 of $61(21 \%)$ listed cases were noted to have some degree of slowing on NCS. In our study, $50 \%$ of patients were noted with slow conduction velocities or prolonged distal latencies. In addition, 3 of 12 patients were noted to have low amplitudes (two of three with motor and sensory involvement), a finding not previously reported that may be indicative of axonal loss. The EMG findings are more difficult to directly compare, because there are significant differences in sampling and reporting methods between laboratories. For example, mixed myopathic and neuropathic pattern was reported in 15 historical cases. The exact definition of "neuropathic" and "neurogenic" is unclear and it is not known whether this implies the presence of spontaneous muscle membrane activity or simply describes motor unit morphology and recruitment. However, as our data and that of others reveals, weakness and electrodiagnostic abnormalities seem more likely to occur with advancing age. ${ }^{9-11}$

The information collected here provides new information about GSD III and its effects on nerve and muscle. Previous publications have not found such a strong link between advancing age and neuromuscular dysfunction. In our series of patients, only two of five pediatric patients with GSD IIIa (Patients 1 and 3) had an abnormality on clinical or electrodiagnostic examinations. The abnormality in both patients was mild slowing of a single motor response. Despite elevated CPK levels in the five patients who are younger than 18 years, weakness and EMG abnormalities were not present. This limited sample suggests that CPK elevation does not correlate well with weakness or electrodiagnostic abnormalities in children, although further study is needed. In addition, the knowledge that weakness is more likely to appear with increasing age suggests that serial neurologic and electrodiagnostic examinations may be appropriate as early identification of these abnormalities might have implications for treatment. For example, the finding of myopathy in an asymptomatic patient would serve as a call to pro- 
Table 3 Summary of previously reported electrodiagnostic findings in GSD III

\begin{tabular}{|c|c|c|c|}
\hline Study & $\mathrm{N}$ & NCS findings & EMG findings \\
\hline Coleman et al. ${ }^{9}$ & 13 & Slowed velocities in two patients & Myopathic $^{a}$ MUPs, some SA \\
\hline Di Mauro et al. ${ }^{10}$ & 5 & $\begin{array}{l}\text { Slowed motor and sensory velocities in } \\
\text { two patients }\end{array}$ & Myopathic MUPs Prominent SA in four patients \\
\hline Kiechl et al. ${ }^{11}$ & 4 & Slowed velocities in two patients & Myopathic MUPs Neuropathic MUPs SA \\
\hline Kotb et al. ${ }^{25}$ & 3 & Mild to moderate slowing in motor nerves & $\begin{array}{l}\text { Mixed myopathic and neuropathic }{ }^{b} \text { pattern in } \\
\text { two patients, SA present }\end{array}$ \\
\hline Momoi et al. ${ }^{26}$ & 19 & Information not available & $\begin{array}{l}\text { Mixed myopathic and neurogenic pattern in } 9 \text { of } \\
19 \text { patients who had EMG }\end{array}$ \\
\hline Moses et al. ${ }^{23}$ & 16 & $\begin{array}{l}\text { Prolonged DL of motor/sensory nerves in } \\
\text { three patients }\end{array}$ & $\begin{array}{l}\text { Myopathic MUPs in six of nine patients with } \\
\text { EMG Prominent SA in three }\end{array}$ \\
\hline Ugawa et al. ${ }^{24 c}$ & 1 & $\begin{array}{l}\text { Slowing in upper and lower extremity } \\
\text { motor nerves }\end{array}$ & Myopathic MUPs \\
\hline \multicolumn{4}{|c|}{$\begin{array}{l}\text { SA, spontaneous activity. } \\
{ }^{a} \text { Myopathic motor unit potentials defined by short duration, low amplitude, increased complexity and early recruitment. } \\
{ }^{b} \text { Neuropathic motor unit potentials defined by long duration, large amplitude and late (reduced) recruitment. } \\
{ }^{c} \text { Report included in Momoi et al., }{ }^{26} \text { but NCS results not detailed. }\end{array}$} \\
\hline
\end{tabular}

mote more aggressive dietary therapy. An alternative explanation for our findings is that pediatric patients may not have received as an extensive electrodiagnostic evaluation as the adult patients in the cohort.

Perhaps the most interesting finding in our patient cohort is the occurrence of NCS and EMG changes in the two adult GSD IIIb patients (cases 9 and 12) with normal clinical examinations. Both GSD IIIb patients in this series had evidence of carpal tunnel syndrome and mild myopathic changes in lower extremity muscles. By definition, muscle dysfunction is not expected in GSD IIIb and muscle involvement was much less pronounced in the IIIb patients than in those with IIIa. Further study is needed to determine whether GSD IIIb patients are prone to carpal tunnel syndrome and mild myopathy with advancing age and why this might occur. Given the fact that both patients had prior muscle biopsies demonstrating normal glycogen content and structure with normal debranching enzyme activity, any muscle involvement must result from yet unrecognized mechanisms such as synergistic heterozygosity, a finding seen in other situations such as in patients with fatty acid oxidation disorders. The neuropathic findings are certainly the more prominent feature in both patients and may result from glycogen deposition in nerve, which has been previously documented. ${ }^{24}$ If changes in nerve and muscle are eventually shown to be associated with GSD IIIb in a larger cohort, serial clinical or electrodiagnostic screenings would be important as early intervention could prevent the development of permanent sensory and motor loss. No change in the current GSD III classification system would be necessary, because it is based on markers of muscle glycogen metabolism, not clinical or electrodiagnostic findings.

Another finding unique to this data are the marked intrinsic hand muscle involvement seen. GSDs normally cause myopathy, which typically results in a limb-girdle distribution of weakness. Although earlier reports have mentioned atrophy of distal muscles and finger weakness in GSD III, detailed accounts of intrinsic hand muscle involvement are lacking and it is difficult to determine the etiology. ${ }^{10,11,26,27}$ In our study, 3 of 12 patients demonstrated intrinsic hand muscle weakness at the time of examination, whereas 7 of 12 had abnormalities in median or ulnar NCS or neuropathic changes on EMG of the abductor pollicis brevis. These findings seem to be secondary to a combination of neuropathy and myopathy. Although carpal tunnel syndrome may account for some of the abnormalities in Patient 9, it does not explain the appearance of myopathic motor unit potentials in the abductor pollicis brevis (Patients 7 and 8) or low amplitude median motor responses in the absence of median sensory abnormalities (Patient 8). A larger series of patients will be required to better determine the etiology of intrinsic hand muscle weakness in GSD III. Identifying and treating this weakness is important to patients' functioning and quality of life.

Our data also provide more evidence to support the notion that GSD III may cause a sensorimotor polyneuropathy. This has been reported in both children and adults with GSD III and is believed to be secondary to glycogen deposition in axons, although features of demyelination have been reported as well. ${ }^{17,18}$ Six patients reviewed here had abnormalities on NCS. Although these abnormalities occurred more frequently in motor responses, the presence of slowing cannot be explained by myopathy. Only one patient had clinical evidence of sensory loss and features consistent with sensorimotor polyneuropathy on electrodiagnostic examination. Of note, this individual was the oldest GSD IIIa patient studied (Patient 11, 53 years). As with myopathy, involvement of sensory nerves may be more likely to occur with advancing age.

The major weaknesses of this study arise from its retrospective nature. Only a small number of GSD III patients underwent electrodiagnostic evaluation (12 of 40). This may have created a selection bias for patients more likely to be experiencing neuromuscular manifestations of disease. A second weakness was the lack of a standardized protocol for assessing GSD III. Patients studied in the last few years received a more detailed evaluation, likely reflecting our evolving knowledge of the disease. Finally, as these patients were seen over the course of nearly two decades, it is unlikely that they were all treated by current consensus guidelines. The effects of appropriate management of GSD III on the development of neuromuscular disease are unknown. 
Further efforts are underway to study all GSD III patients at our center using a standardized nerve conduction study/EMG protocol. The design is based on the data presented here and will focus on both myopathic and neuropathic involvement. This will permit better comparison and provide a broader sampling of our GSD III population. It will also provide longitudinal information on this disorder in many of the patients reported here. Given the small number of patients with GSD III, collaboration with other centers may be necessary to fully elucidate the neuromuscular effects of debrancher deficiency and assess the impact of early identification upon management and prognosis. In addition, further work is also necessary to determine whether nerve and muscle involvement commonly occur in GSD IIIb.

\section{ACKNOWLEDGMENTS}

This project was partly funded by a research grant from Association for Glycogen Storage Diseases (AGSD), United States. We thank the Duke Clinical Research Unit for their assistance. We are grateful to our GSD III patient population, for their willingness to participate in this study.

\section{REFERENCES}

1. Yang-Feng TL, Zheng K, Yu J, Yang BZ, Chen YT, Jao FT. Assignment of the human glycogen debranching gene to chromosome 1p21. Genomics 1992;13:931-934.

2. Talente GM, Coleman RA, Alter C, et al. Glycogen storage disease in adults. Ann Intern Med 1994;120:218-226.

3. Parvari R, Moses S, Shen J, Hershkovitz E, Lerner A, Chen YT. A singlebase deletion in the $3^{\prime}$-coding region of glycogen-debranching enzyme is prevalent in glycogen storage disease type IIIA in a population of North African Jewish patients. Eur J Hum Genet 1997;94:1866-1871.

4. Zimakas PJA, Rodd CJ. Glycogen storage disease type III in Inuit children. CMAJ 2005; 172:355-358.

5. Santer R, Kinner M, Steuerwald U, et al. Molecular genetic basis and prevalence of glycogen storage disease type IIIa in the Faroe Islands. Eur $J$ Hum Genet 2001;9:388-391.

6. Shen JJ, Chen YT. Molecular characterization of glycogen storage disease type III. Curr Mol Med 2002;2:167-175.

7. Bao Y, Yang BZ, Dawson TL Jr, Chen YT. Isolation and nucleotide sequence of human liver glycogen debranching enzyme mRNA: identification of multiple tissue-specific isoforms. Gene 1997;197:389-398.

8. Wolfsdorf JI, Holm IA, Weinstein DA. Glycogen storage diseases: phenotypic, genetic, and biochemical characteristics. Endocrinol Metab Clin North Am 1999;28:801-823.

9. Coleman RA, Winter HS, Wolf B, Gilchrist JM, Chen YT. Glycogen storage disease type III (glycogen debranching enzyme deficiency): correlation of biochemical defects with myopathy and cardiomyopathy. Ann Intern Med 1992;116:896-900.
10. Di Mauro S, Hartwig GB, Hays A, et al. Debrancher deficiency: neuromuscular disorder in 5 adults. Ann Neurol 1979;5:422-436.

11. Kiechl S, Kohlendorfer U, Thaler C, et al. Different clinical aspects of debrancher deficiency myopathy. J Neurol Neurosurg Psychiatry 1999;67: 364-368.

12. Goldberg T, Slonim AE. Nutrition therapy for hepatic glycogen storage disease. J Am Diet Assoc 1993;93:1423-1430.

13. Chen YT, Burhchell A. Glycogen storage diseases. In: Scriver CR, Beaudet AL, Sly WS, Valle D, editors. The metabolic and molecular bases of inherited disease. New York: McGraw-Hill, Inc., Health Professions Division, 2001:935-966.

14. Demo E, Frush D, Gottfried M, et al. Glycogen storage disease type III-hepatocellular carcinoma a long-term complication? J Hepatol 2007;46: 492-498.

15. Shimizu J, Shiraishi H, Sakurabayashi S, et al. A report on an adult case of type III glycogenosis with primary liver cancer and liver cirrhosis. Nippon Shokakibyo Gakkai Zasshi 1982;79:2328-2332.

16. Haagsma EB, Smit GPA, Niezen-Koning KE, et al. Type IIIb glycogen storage disease associated with end-stage cirrhosis and hepatocellular carcinoma. Hepatology 1997;25:537-540.

17. Siciliano M, De Candia E, Ballarin S, et al. Hepatocellular carcinoma complicating liver cirrhosis in type IIIa glycogen storage disease. $J$ Clin Gastroenterol 2000;31:80-82.

18. Cosme A, Montalvo I, Sánchez J, et al. Type III glycogen storage disease associated with hepatocellular carcinoma. Gastroenterol Hepatol 2005;28: $622-625$.

19. Coleman RA, Winter HS, Wolf B, Chen YT. Glycogen debranching enzyme deficiency: long-term study of serum enzyme activities and clinical features. $J$ Inherit Metab Dis 1992;15:869-881.

20. Fellows IW, Lowe JS, Ogilvie AL, Stevens A, Toghill PJ, Atkinson M. Type III glycogenosis presenting as liver disease in adults with atypical histological features. J Clin Pathol 1983;36:431-434.

21. Markowitz AJ, Chen YT, Muenzner J, Delbuono EA, Lucey MR. A man with type III glycogenosis associated with cirrhosis and portal hypertension. Gastroenterology 1993;105:1882-1885.

22. Murase T, Ikeda H, Muro KN, Sugita H. Myopathy associated with type III glycogenosis. J Neurol Sci 1973;20:287-295.

23. Moses SW, Gadoth N, Bashan N, Ben-David E, Slonim A, Wanderman KL. Neuromuscular involvement in glycogen storage disease type III. Acta Paediatr Scand 1986;75:289-296.

24. Ugawa Y, Inoue K, Takemura T, Iwamasa T. Accumulation of glycogen in sural nerve axons in adult-onset type III glycogenosis. Ann Neurol 1994;9: 294-297.

25. Kotb MA, Abdallah HK, Kotb A. Liver glycogenosis: are they a possible cause of polyneuropathy? A cross-sectional study. J Trop Pediatr 2004;50: 196-202.

26. Momoi T, Sano H, Yamanaka C, Sasaki H, Mikawa H. Glycogen storage disease type III with muscle involvement: reappraisal of phenotypic variability and prognosis. Am J Med Genet 1992;42:696-699.

27. Shaiu WL, Kishnani P, Shen J, Liu HM, Chen YT. Genotype-phenotype correlation in two frequent mutations and mutation update in type III glycogen storage disease. Mol Genet Metab 2000;69:16-23.

28. Forbes GB. Glycogen storage disease: a report of a case with abnormal glycogen structure in liver and skeletal muscle. J Pediatr 1953;42:645-653. 